\title{
Downregulation of HDGF inhibits the tumorigenesis of bladder cancer cells by inactivating the PI3K-AKT signaling pathway
}

This article was published in the following Dove Press journal: Cancer Management and Research

\author{
Cong Zhang ${ }^{1,2}$ \\ Xiangping Chang' \\ Dongshan Chen' \\ Feilong Yang ${ }^{3}$ \\ Zeyan $\mathrm{Li}^{1}$ \\ Dawei Li' \\ Nengwang $\mathrm{Yu}^{\prime}$ \\ Lei Yan' \\ Hainan Liu' \\ Zhonghua $\mathrm{Xu}^{\prime}$ \\ 'Department of Urology, Qilu Hospital of \\ Shandong University, Jinan 2500I2, \\ People's Republic of China; ${ }^{2}$ Key \\ Laboratory of Cardiovascular \\ Remodeling and Function Research, \\ Shandong University, Jinan, People's \\ Republic of China; ${ }^{3}$ Department of \\ Urology, Peking University Third \\ Hospital, Beijing I0019I, People's \\ Republic of China
}

Correspondence: Dawei Li Department of Urology, Qilu Hospital of Shandong University, Wenhuaxi Road 107\#, Jinan 250012, People's Republic of China

Tel +8653182166701

Fax +8653182169044

Email lidaweimd@aliyun.com
Background: Hepatoma-derived growth factor (HDGF) is a heparin-binding protein that has been observed to be abnormally expressed in numerous malignancies, but the definite role of HDGF in bladder cancer (BCa) has not been clarified. Here, we conduct the present study to evaluate correlations between HDGF and $\mathrm{BCa}$.

Methods: Bioinformatics analysis was used to evaluate HDGF expression levels in $\mathrm{BCa}$ tissues. The effect of HDGF on cell proliferation, migration, invasion, cell cycle and apoptosis was analyzed utilizing CCK-8, clone formation, Transwell assays and flow cytometry, respectively. In addition, the xenograft tumor model was established.

Results: Based on bioinformatics analysis, we noticed that HDGF was highly expressed in $\mathrm{BCa}$ tissues and was positively correlated with poor prognosis in patients. Knockdown of HDGF markedly reduced tumorigenesis in BCa cells. Furthermore, the results of flow cytometry showed that HDGF deletion enhanced apoptosis in T24 and 253J cells and led to cell cycle arrest in G1 phase. In further studies, we found that tumor growth was inhibited in xenograft nude mouse models with HDGF deletion. The results of RNA-seq analysis revealed that the PI3K-AKT signaling pathway-related genes were obviously changed in HDGF-deficient 253J cells, and this result was further confirmed by Western blot analysis.

Conclusion: In summary, we suggest that HDGF plays a substantial role in $\mathrm{BCa}$ and promotes tumor development and progression by regulating the PI3K-AKT signaling pathway, which provides a promising target for $\mathrm{BCa}$ treatment.

Keywords: HDGF, bladder cancer, tumorigenesis, PI3K/AKT signaling

\section{Introduction}

Bladder cancer $(\mathrm{BCa})$ is one of the most common malignant tumors in humans, and it is ranked first among all urologic tumors worldwide. ${ }^{1}$ The number of patients newly diagnosed with $\mathrm{BCa}$ is approximately 549,393, and 199,922 patients died from tumor progression in the last year. ${ }^{2} \mathrm{BCa}$ is generally classified into muscleinvasive bladder cancer (MIBC) and non-muscle-invasive bladder cancer (NMIBC). ${ }^{3}$ The current standard treatments for MIBC and NMIBC are transurethral resection of bladder tumor (TURBT) and radical cystectomy, respectively, with or without postoperative cisplatin-based combination chemotherapy. ${ }^{4-7}$ However, due to high recurrence, ${ }^{8}$ the cost and curative effect of $\mathrm{BCa}$ are still unsatisfactory. Considering early diagnosis and effective treatment, it remains urgent to identify novel cytogenetic molecules for BCa. 
HDGF is an acidic heparin-binding protein that was first identified from the cell line Hun-7. ${ }^{9,10}$ HDGF belongs to a new family of growth factors called HDGF-related proteins ${ }^{11}$ and can transport to the nucleus, where it functions as a transcription factor, via nuclear localization signals. ${ }^{12,13}$ Overexpression of HDGF has been found to be associated with many human cancers, such as lung cancer, gastrointestinal stromal cancer, pancreatic cancer, and gastric carcinoma, ${ }^{14-17}$ but the correlation between HDGF and BCa remains unknown.

We conducted the present study to assess HDGF expression levels in $\mathrm{BCa}$ patients. The relationship between HDGF level and patient prognosis was analyzed utilizing a public gene expression database - ONCOMINE microarray datasets (https://www.oncomine.org). We further silenced the expression of HDGF using lentiviral shRNA to investigate the function and mechanism of HDGF in vitro and in vivo. We hypothesize that HDGF is strongly correlated with $\mathrm{BCa}$ carcinogenesis in vitro and in vivo and that HDGF may be a potential therapeutic target for the diagnosis and prognosis of $\mathrm{BCa}$.

\section{Materials and methods}

\section{Bioinformatic analysis of the HDGF in $\mathrm{BCa}$}

The mRNA level of HDGF in $\mathrm{BCa}$ was analyzed via ONCOMINE microarray datasets (https://www.oncomine. org). The datasets play a powerful role in screening differentially expressed genes (DEGs) in tumor and normal tissues. By searching "HDGF", "BCa", "Cancer vs Normal Analysis" and "mRNA", 3 datasets with 7 subunits were included in the present analysis. Based on the above datasets, a meta-analysis was performed to compare HDGF expression between cancer and normal tissues. In addition, we further compared the level of HDGF between MIBC and NMIBC tissues based on DB3 and Lee bladder datasets. IHC results of HDGF in $\mathrm{BCa}$ and normal tissue are available in public database-The Human Protein Atlas portal (www.proteinatlas.org). ${ }^{18}$ The survival information of patients was obtained from the Lee bladder dataset.

\section{Cell culture}

The human bladder cancer cell lines T24 and 253J were purchased from the American Type Culture Collection (Manassas, VA, USA). The two cell lines, T24 and 253J, were cultured in PRMI-1640 medium (Gibco, USA) supplemented with 10\% fetal bovine serum (FBS) (Gibco,
Australia). The cells were maintained at $37{ }^{\circ} \mathrm{C}$ in a humidified incubator with a constant air flow of $5 \% \mathrm{CO} 2$.

\section{Recombinant lentivirus}

The recombinant lentivirus short hairpin RNA targeted hume HDGF sequence (Lv-shHDGF) or non-silencing control sequence (Lv-shCon) were purchased from Bio-link-gene Inc. (Shanghai, China). The target sequences of Lv-shHDGF and Lv-shCon were 5'- AACCGGCAGAAGGAGTACAAA$3^{\prime}$ and $5^{\prime}$-TTCTCCGAACGTGTCACGT-3', respectively.

\section{Cellular infection of lentivirus}

In brief, T24 and 253J cells were cultured in complete medium containing recombinant lentivirus (Lv-shHDGF or Lv-shCon) for $12 \mathrm{hrs}$; then, the medium was replaced with normal medium. As observed by a fluorescence microscope, the proportion of GFP-positive cells represented the infection efficiency. The culture medium containing puromycin (Solarbio, Beijing, China) was used to kill cells that were unsuccessfully transfected with virus.

\section{Quantitative real-time PCR}

Total RNA was extracted from the cells using an RNAQuick purification Kit (ES Science, China), and the RNA was reverse transcribed into complementary DNA (cDNA) using a qPCR RT kit (TOYOBO, Japan). The cDNA was used for RT-PCR assays (SYBR Green Master Mix; YESEN, Shanghai, China) according to the manufacturer's instructions. Relevant data were analyzed with the $2^{-\Delta \Delta C t}$ method normalized to $\beta$-actin. The primers for HGDF were 5'-CTCTTCCCTTACGAGGAATCCA-3' (forward) and 5'-CCTTGACAGTAGGGTTGTTCTC-3' (reverse).

\section{Western blot analysis}

T24 and 253J cells with stable HDGF knockdown and control plasmid expression were collected and lysed in RIPA buffer (Beyotime, Shanghai, China), and Western blot assay of lysates of equal mass was performed as described previously. ${ }^{19}$ The following antibodies were used: anti-HDGF, E-cadherin, N-cadherin, P53, Bax, Bcl2, PI3K, AKT, p-AKT, $\beta$-actin and GAPDH (all 1:2000) (CST, USA).

\section{CCK-8 cell proliferation assays}

T24 and 253J cells infected with Lv-shHDGF or Lv-shCon were seeded in 96-well plates at a density of 2000 cells/well and incubated in a culture chamber at $37{ }^{\circ} \mathrm{C}$ for $1,2,3,4$ or 5 days. Then, the optical density (OD) was measured at 
$450 \mathrm{~nm}$ using a microplate reader (Bio-Rad Laboratories Inc., Hercules, CA, USA). Each group consisted of five duplicates, and the experiment was performed in triplicate.

\section{Colony formation assays}

Cells infected with Lv-shHDGF or Lv-shCon lentivirus were seeded in six plants (T24: 600/well; 253J: 1000/ well, respectively). After 14 days of culture, the cells were fixed with $4 \%$ paraformaldehyde for 30 mins. After washing with PBS again, the colonies were stained with $5 \%$ crystal violet for 30 mins. Colonies exceeding 50 cells were counted using ImageJ. Each group consisted of three duplicates, and the experiment was performed three times.

\section{Cell migration assays}

T24 and 253J cells were digested with trypsin (Gibco, USA) and dissociated repeatedly to prepare a single cell suspension. Migration assays were performed as described previously. ${ }^{20}$ After rubbing away the cells failed to through the membrane and washing with PBS three times, these chambers were photographed using an upright fluorescence microscope. Three random fields of vision were adopted for counting, and each experiment was performed in triplicate.

\section{Cell invasion assays}

The invasion assay procedure was similar to the migration assay procedure. However, the chambers used in the invasion assay were coated with diluted Matrigel (BD Bioscience, USA). The incubation times for the T24 and $253 \mathrm{~J}$ cells were $36 \mathrm{~h}$ and $72 \mathrm{~h}$, respectively.

\section{Cell cycle analysis}

Cells were harvested by trypsinization and fixed with $75 \%$ cold ethanol for $24 \mathrm{~h}$ at $4{ }^{\circ} \mathrm{C}$. The next day, the cells were resuspended in $100 \mu \mathrm{L}$ RNaseA (Solarbio, Beijing, China) at $37{ }^{\circ} \mathrm{C}$ for 30 mins. Then, the cells were stained with $400 \mu \mathrm{L}$ propidium iodide (Solarbio, Beijing, China) at $4^{\circ}$ $\mathrm{C}$ for $30 \mathrm{mins}$ in the dark. Cell cycle distribution was recorded with a flow cytometer (BD Bioscience, USA).

\section{Cell apoptosis analysis}

Cells were harvested, washed with cold PBS, and resuspended in $400 \mu \mathrm{L} 1 \times$ binding buffer (BD Bioscience, USA) Next, $100 \mu \mathrm{L}$ of the cell solution was transferred into a $5 \mathrm{~mL}$ culture tube, and $5 \mu \mathrm{L}$ of PE Annexin V and $5 \mu \mathrm{L}$ of 7-AAD (BD Bioscience, USA) were added to the culture tube. Cells were incubated for 15 mins at room temperature in the dark, and $400 \mu \mathrm{L}$ of $1 \times$ binding buffer was added to each tube. The apoptosis of cells was analyzed in triplicate by flow cytometry (BECKMAN COULTER, USA) according to the manufacturer's instructions.

\section{In vivo xenograft assays}

Female nude mice were purchased from the Model Animal Research Center of Nanjing University and housed in specific pathogen-free barrier facilities. Twelve four-week-old female nude mice were randomly divided into two groups. A total of $5 \times 10^{6} \mathrm{~T} 24$ cells infected with Lv-shHDGF were injected into the right axilla of six mice, and six other mice were injected with equal concentration of T24 cells infected with $\mathrm{Lv}$-shCon. The diameters of the xenografts were measured using a slide caliper every 3 days for 27 days. The xenograft tumor volume was calculated using the formula: $\mathrm{V}=\left(\right.$ length $\times$ width $\left.^{2}\right) / 2$. At the end of the experiment, mice were euthanized and imaged. The xenograft tumors were removed from each mouse, imaged, weighed, and fixed in $4 \%$ paraformaldehyde.

All animal studies were approved by The Institutional Animal Care and Use Committee of the Shandong University and all animal studies were carried out in accordance with the UK Animal (Scientific Procedures) Act, 1986 and associated guidelines.

\section{Immunohistochemistry (IHC) staining}

The nude mouse xenograft tumors were paraffin embedded and sliced into $4 \mu \mathrm{m}$ thick paraffin sections. Then, these tumor tissues were subjected to IHC staining as previously described. ${ }^{21}$ HDGF primary antibody (1:100, Abcam, USA) and Ki-67 antibody (1:200, ZhongShan Bio-Tech, China) were used. The signal intensity was scored using the following criteria: $0=$ negative, $1=$ weak, $2=$ moderate, and $3=$ strong. The percentage of stained cells was scored as follows: $1=0 \%, 2=25-50 \%, 3=51-75 \%$, and $4=76-$ $100 \%$. The final staining scores were calculated as the intensity $\times$ the staining percentage.

\section{RNA sequencing analysis}

The 253J cells infected with Lv-shHDGF or Lv-shCon were collected, and the total RNA was extracted using TRIzol (Invitrogen, Carlsbad, CA, USA). Library construction and sequencing were performed by Annoroad Gene Technology Inc. (Beijing, China). The libraries were sequenced using the IIIumina platform. DEGs were screened according to the following criteria: a $p<0.05$ and an absolute fold change $>2.0$. The intracellular signing 
pathway was determined using KEGG based on DEGs, and protein-protein interaction analysis (PPI) was performed.

\section{Statistical analysis}

The data presented as the mean \pm SD were analyzed by Student's $t$-test. The correlations between HDGF expression level and the clinicopathological features of $\mathrm{BCa}$ patients were analyzed using the independent-sample $\mathrm{T}$ test. In addition, the CCS analysis was performed by Kaplan-Meier analysis. The Statistical Package for Social Science version 21 (SPSS Inc. Chicago, IL, USA) and GraphPad Prim 5 software (GraphPad Software Inc., Sam Diego, CA, USA) were used, and $p<0.05$ was considered statistically significant.

\section{Results}

\section{HDGF was elevated in $\mathrm{BCa}$ tissues}

To evaluate the potential role of $\mathrm{HDGF}$ in $\mathrm{BCa}$, the ONCOMINE microarray database was utilized. Three databases were included, and a meta-analysis was performed based on these data. As shown in Figure 1A, it was obvious that the expression level of HDGF was higher in $\mathrm{BCa}$ tissues than in normal tissues $(p<0.001)$. The information acquired from the DB3 and Lee Bladder databases indicated that MIBC tissues showed elevated HDGF levels compared to NMIBC and normal tissues (Figure 1B and $\mathrm{C}$ ). IHC results acquired from The Human Protein Atlas portal indicated that HDGF was highly expressed in BCa compared to normal (Figure S1). BCa patients with HDGF overexpression were found to be correlated with poor Cancer-specific survival (CSS) but not overall survival (OS) (Figure 1D and E).

\section{Associations between HDGF expression level and clinicopathological features of $\mathrm{BCa}$ patients}

A total of $165 \mathrm{BCa}$ patients and their essential information, such as age, sex, pathological stage, pathological grade, and survival time, were included in the present study. The correlations between HDGF level and clinical characteristics of the $165 \mathrm{BCa}$ patients were further evaluated. We found that high HDGF levels were strongly associated with muscular invasion, lymph node metastasis, pathological grading, progression and CCS (all $p \leq 0.05$ ). Although patients with older age, recurrence and poor OS also showed higher HDGF levels, these differences were not statistically significant $(p>0.05)$. All results are shown in Table 1.

\section{HDGF expression levels were} downregulated by lentivirus-mediated shRNA in BCa cells

The infection efficiency of bladder cancer cells $>90 \%$ identified by GFP expression was considered to be satisfactory (Figure 2A). The mRNA and protein levels of HDGF in T24 and 253J cells infected with Lv-shHDGF were obviously decreased (Figure 2B-E). These results indicated that the expression of HDGF was knocked down successfully.

\section{Knockdown of HDGF suppressed $\mathrm{BCa}$ cell proliferation and clone formation in vitro}

The proliferation of T24 cells infected with Lv-shHDGF was significantly suppressed compared to that of control cells according to the CCK-8 assay, and similar results were found in 253J cells (Figure 3A). Moreover, a cloning assay was performed to analyze the role of HDGF in $\mathrm{BCa}$ cell colony formation. As shown in Figure $3 \mathrm{~B}$ and $\mathrm{C}$, the clonogenic capacity in Lv-shHDGF-infected cells was dramatically impaired. Indeed, our results demonstrated that HDGF was important for T24 and 253J cell proliferation and colony formation.

\section{HDGF depletion reduced migration and invasion in $\mathrm{BCa}$ cell lines}

Transwell assays indicated that HDGF knockdown significantly reduced the migration and invasion capability of T24 and 253J cell lines (Figure 3D-G). Furthermore, key proteins related to epithelial-mesenchymal transition (EMT) were analyzed by Western blot, and the results indicated that HDGF knockdown increased the expression of E-cadherin but decreased the levels of $\mathrm{N}$-cadherin and vimentin (Figure $3 \mathrm{H}$ and I). These findings demonstrated that HDGF deletion was significantly associated with the impairment of $\mathrm{BCa}$ cell migration and invasion abilities.

\section{Disruption of HDGF expression inhibited the cell cycle in BCa cells}

The results described above indicate that HDGF plays a substantial role in the proliferation of $\mathrm{BCa}$ cells; therefore, flow cytometry was conducted to identify whether 
Comparison of HDGF across 7 analyses

A

Over-expression

Median rank $P$-value Gene

569.0 4.90E-7 HDGF

\begin{tabular}{|l|l|l|l|l|l|l|}
\hline 1 & 2 & 3 & 4 & 5 & 6 & 7 \\
\hline
\end{tabular}

$1 \quad 5 \quad 1025 \quad 2510 \quad 5 \quad 1$

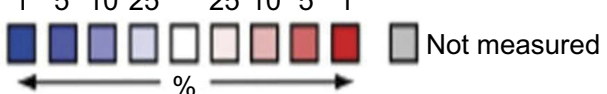

The rank for a gene is the median rank for that gene across each of the analyses. The $P$-value for a gene is its $P$-value for the median-ranked analysis.

Legend

1. Infiltrating bladder urothelial carcinoma 5 . Superficial bladder cancer vs. normal vs. normal Lee bladder, J Clin Oncol,2010

Dyrskjot bladder 3, Cancer res, $2004 \quad$ 6. Infiltrating bladder urothelial carcinoma

2. Stage ois bladder urothelial cancinoma vs. vs. normal

normal Sanchez carbayo bladder 2, J Clin Oncol,

Dyrskjot bladder 3, Cancer res, $2004 \quad 2006$

3. Superficial bladder cancer vs. normal 7. Superficial bladder cancer vs. normal Dyrskjot bladder 3, Cancer res, 2004 Sanchez carbayo bladder 2, J Clin Oncol,

4. Infiltrating bladder urothelial carcinoma 2006 vs. normal

Lee bladder, J Clin Oncol,2010

C Lee bladder database

B

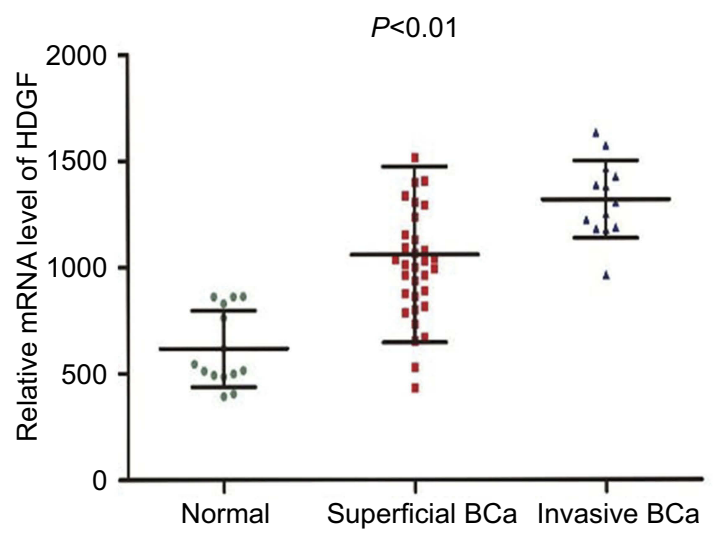

D

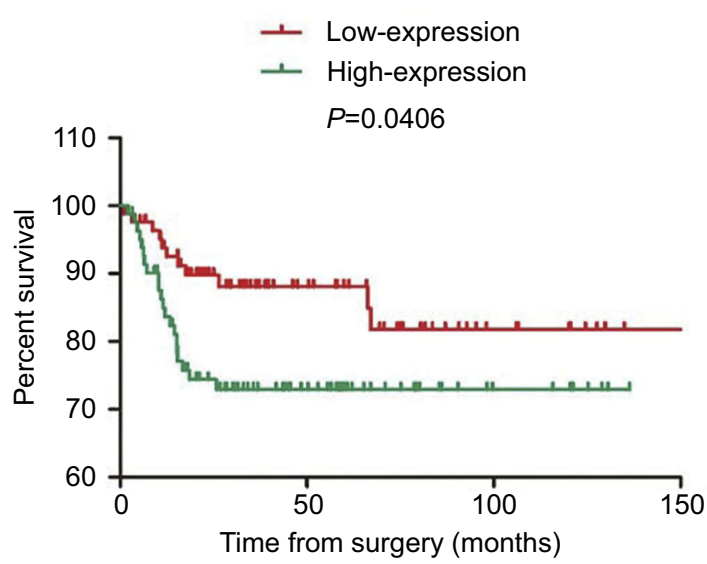

E

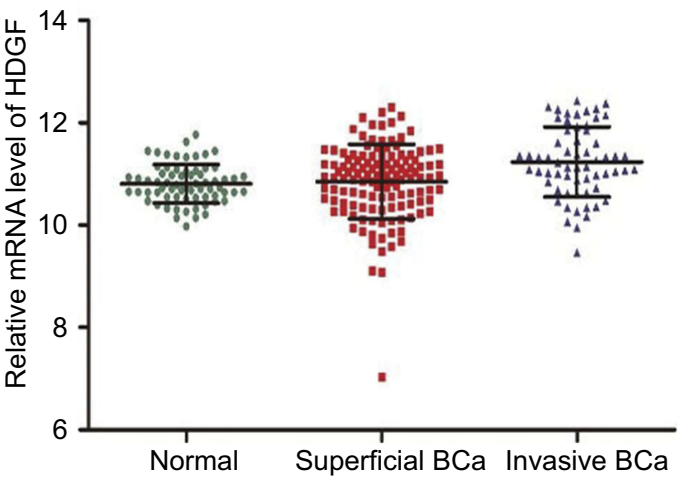

Overall survival

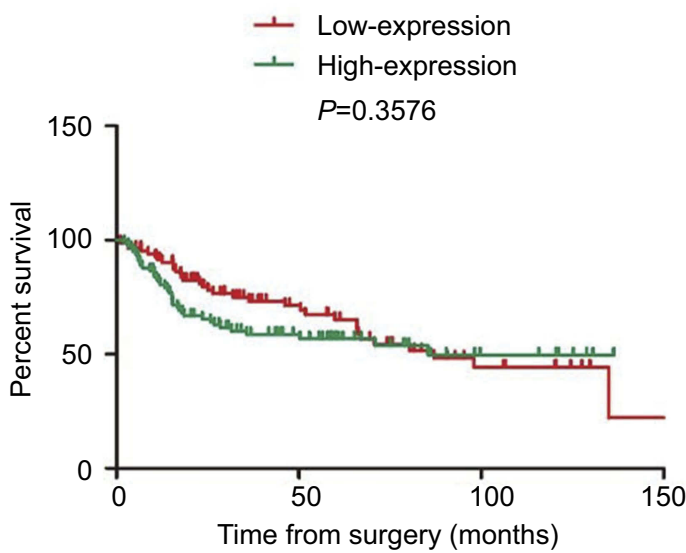

Figure I Expression of HDGF is higher in BCa tissue and appears to be closely related to muscle invasion and CCS (All the data from ONCOMINE database). (A) Metaanalysis of the HDGF mRNA expression between the BCa and normal urothelial tissue $(p<0.00 \mathrm{I})$. (B and $\mathbf{C})$ HDGF expression is elevated in MIBC compared to NMIBC and normal tissues according to DB3 and Lee Bladder databases $(p<0.0 I)$. (D and $\mathbf{E})$ The Kaplan-Meier analysis indicates overexpression of HDGF predicts poor CCS but not OS using Lee Bladder database.

Abbreviations: HDGF, Hepatoma-derived growth factor; BCa, Bladder cancer; CCS, Cancer-specific survival; OS, Overall survival.

HDGF plays a role in cell cycle distribution. Interestingly, T24 cells infected with Lv-shHDGF were dramatically arrested in G1 phase compared to control cells, and the number of cells in S and G2 phase decreased. Similar results were observed in 253J cells (Figure 4A and B). Western blotting showed that the 
Table I Clinicopathological parameters and Hepatoma-derived growth factor (HDGF) expression level in $165 \mathrm{BCa}$ patients based on Lee Bladder database

\begin{tabular}{|c|c|c|c|}
\hline Characteristics & $\begin{array}{l}\text { No. of } \\
\text { patients }\end{array}$ & $\begin{array}{l}\text { HDGF } \\
\text { expression } \\
\text { (Mean } \pm \text { SD) }\end{array}$ & $p$-value \\
\hline Patients & 165 & $10.96 \pm 0.75$ & \\
\hline $\begin{array}{l}\text { Age } \\
\qquad 665 y \\
>65 y\end{array}$ & $\begin{array}{l}73 \\
92\end{array}$ & $\begin{array}{l}10.77 \pm 0.76 \\
11.11 \pm 0.72\end{array}$ & 0.610 \\
\hline $\begin{array}{l}\text { Sex } \\
\qquad \text { Man } \\
\text { Female }\end{array}$ & $\begin{array}{l}135 \\
30\end{array}$ & $\begin{array}{l}10.96 \pm 0.68 \\
10.95 \pm 1.03\end{array}$ & 0.974 \\
\hline $\begin{array}{l}\text { Muscular invasion } \\
\text { Negative } \\
\text { Positive }\end{array}$ & $\begin{array}{l}103 \\
62\end{array}$ & $\begin{array}{l}10.79 \pm 0.74 \\
\text { II. } 24 \pm 0.68\end{array}$ & $0.000 *$ \\
\hline $\begin{array}{l}\text { Lymph node } \\
\text { metastasis } \\
\text { Negative } \\
\text { Positive }\end{array}$ & $\begin{array}{l}149 \\
16\end{array}$ & $\begin{array}{l}10.92 \pm 0.76 \\
11.31 \pm 0.59\end{array}$ & $0.049 *$ \\
\hline $\begin{array}{l}\text { Distant metastasis } \\
\text { Negative } \\
\text { Positive }\end{array}$ & $\begin{array}{l}158 \\
7\end{array}$ & $\begin{array}{l}10.96 \pm 0.75 \\
10.87 \pm 0.77\end{array}$ & 0.753 \\
\hline $\begin{array}{r}\text { Grade } \\
\text { Low } \\
\text { High }\end{array}$ & $\begin{array}{l}105 \\
60\end{array}$ & $\begin{array}{l}10.72 \pm 0.72 \\
\text { II. } 37 \pm 0.63\end{array}$ & $0.000 *$ \\
\hline $\begin{array}{l}\text { Recurrence } \\
\text { No } \\
\text { Yes } \\
\text { Missing information }\end{array}$ & $\begin{array}{l}67 \\
36 \\
62\end{array}$ & $\begin{array}{l}10.81 \pm 0.81 \\
\mid 1.27 \pm 0.60 \\
\end{array}$ & 0.598 \\
\hline $\begin{array}{l}\text { Progression } \\
\text { No } \\
\text { Yes }\end{array}$ & $\begin{array}{l}134 \\
31\end{array}$ & $\begin{array}{l}10.88 \pm 0.76 \\
11.27 \pm 0.66\end{array}$ & $0.010^{*}$ \\
\hline $\begin{array}{l}\text { Overall survival } \\
\text { Alive } \\
\text { Death }\end{array}$ & $\begin{array}{l}96 \\
69\end{array}$ & $\begin{array}{l}10.88 \pm 0.76 \\
11.06 \pm 0.74\end{array}$ & 0.122 \\
\hline $\begin{array}{l}\text { Cancer-specific } \\
\text { survival } \\
\text { Alive } \\
\text { Death }\end{array}$ & $\begin{array}{l}133 \\
32\end{array}$ & $\begin{array}{l}\mid 0.87 \pm 0.74 \\
|| .33 \pm 0.7 \mid\end{array}$ & $0.002 *$ \\
\hline
\end{tabular}

Note: $* P<0.05$ is considered significant (the independent-sample $T$ test).

expression levels of the G1 checkpoint proteins cyclin D1 and cyclin E were obviously downregulated with HDGF deletion (Figure 4C). These results suggested that HDGF knockdown inhibited proliferation by inducing T24 and 253J cell cycle arrest in G1 phase.

\section{HDGF downregulation promoted}

\section{apoptosis in BCa cells}

As shown in Figure 4D and E, the distribution of early and late apoptosis was obviously increased in T24 and 253J cells infected with Lv-shHDGF. In addition, checkpoint proteins of apoptosis were detected by Western blot. The levels of P53 and Bax were higher in T24 and 253J cells with downregulated HDGF, but the expression of Bcl-2 was lower (Figure 4F). These results suggest that HDGF silencing induces apoptosis in $\mathrm{BCa}$ cells.

\section{Downregulation of HDGF suppressed $\mathrm{BCa}$ cell growth in vivo}

As shown in Figure 5A-C, the tumor size and weight of nude mice injected with Lv-shHDGF-infected cells were significantly lower than those of control mice. Furthermore, IHC staining indicated that HDGF and $\mathrm{Ki}-67$ levels in HDGF knock-out tumors were decreased (Figure 5D and E). These results demonstrated that HDGF deletion inhibited $\mathrm{BCa}$ cell tumorigenicity in vivo.

\section{HDGF depression regulated the PI3K- AKT pathways}

To further illuminate the mechanism of HDGF in BCa tumorigenesis and progression, RNA-seq was performed. With the cut-off criteria of absolute fold-change $\geq 2.0$ and $q<0.05$, we found that 66 genes were upregulated and 96 genes were downregulated after HDGF deletion (Figure 6A). Then, GO enrichment analysis was performed, and a total of 162 DEGs were categorized into 42 functional groups. Three main GO classification categories, cellular component, biological process and molecular function, contained 13, 20 and 9 functional groups, respectively (Figure 6B). Based on the KEGG database, pathway enrichment was further analyzed. We found that the PI3K-AKT signaling pathway passed the filtering criteria $(p<0.05$, Figure $6 \mathrm{C})$. PPI network analysis demonstrated that HDGF with an 11-gene signature coordinately drove tumor progression in $\mathrm{BCa}$ (Figure 6D).

The RNA-seq results indicated that the mRNA levels of key genes in the PI3K-AKT pathway were obviously changed with HDGF deletion (Figure 7A). Then, the checkpoint protein level of the PI3K-AKT was further verified by Western blotting. As shown in Figure 7B, we found that the levels of PI3K and p-AKT were significantly decreased in cells with downregulated HDGF. 

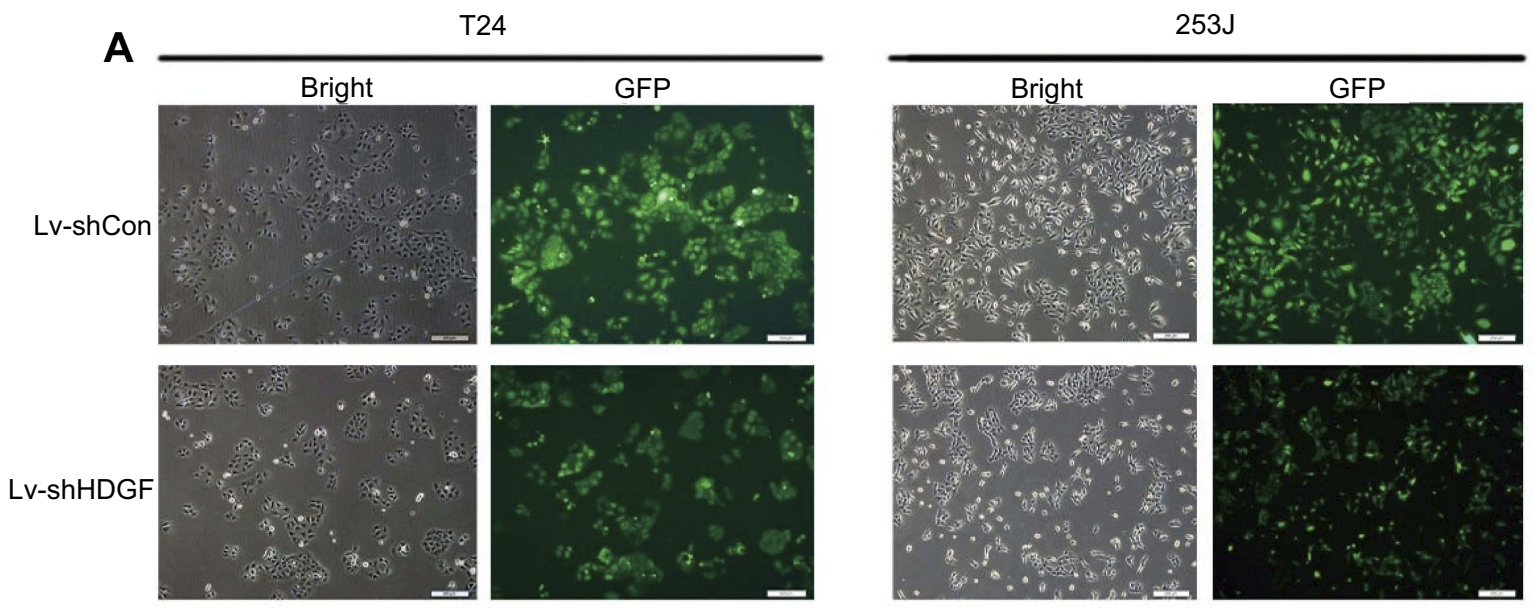

B

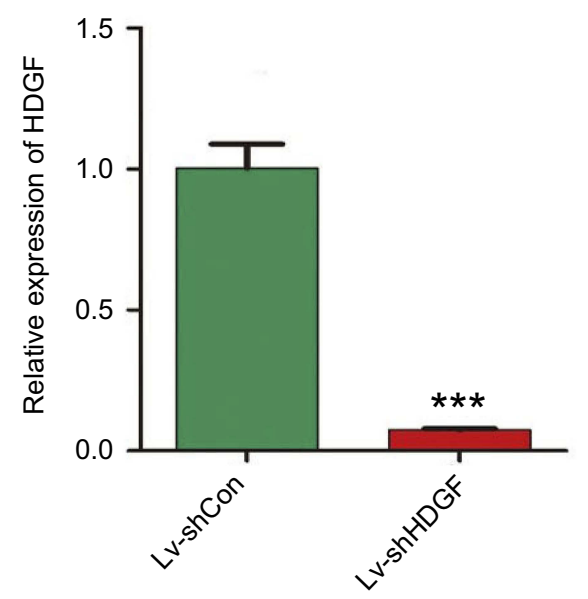

D

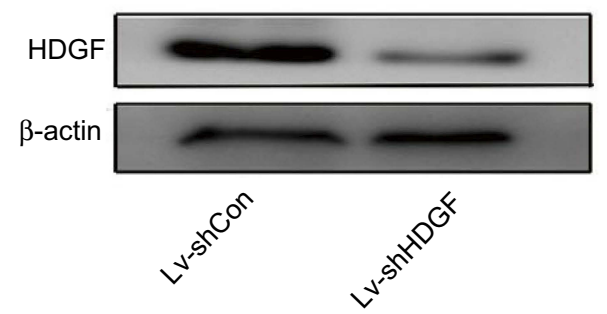

C

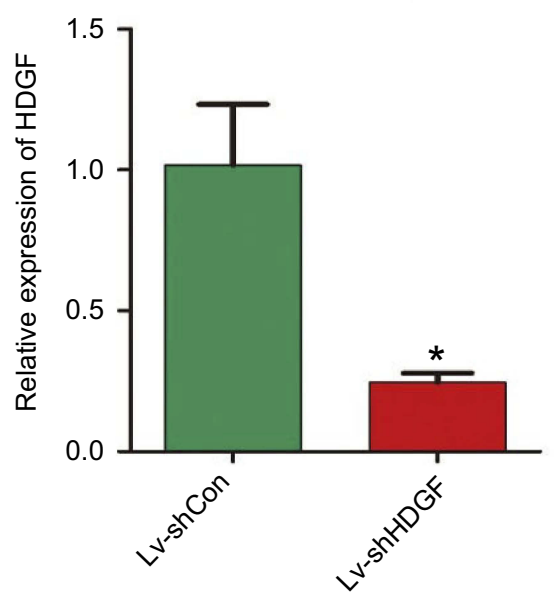

$\mathbf{E}$

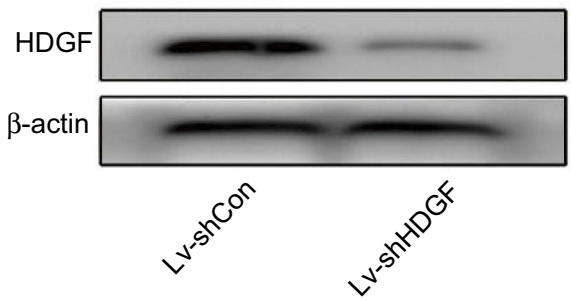

Figure 2 Lentivirus-mediated interference downregulates the expression of Hepatoma-derived growth factor (HDGF) in BCa cells. (A) The bladder cancer cells are examined by fluorescence microscopy after lentivirus infection for $72 \mathrm{~h}$. (B-C) Real-time qPCR indicates mRNA levels are lower in T24 and $253 \mathrm{~J}$ cells infected with LvshHDGF than Lv-shCon. (D-E) The protein levels of HDGF are downregulated in T24 and 253J cells infected with Lv-shHDGF. Every result is verified at least three times. $\left({ }^{*} p<0.05 ; * * * p<0.001\right)$.

\section{Discussion}

Despite the fact that many recent studies have focused on $\mathrm{BCa}, \mathrm{BCa}$ treatment has seen little progress. ${ }^{22}$ Over the past three decades, the five-year survival rate of $\mathrm{BCa}$ has been maintained, with a limited range of clinical therapeutics. ${ }^{22}$ In addition, due to complicated pathological characteristics, inconspicuous early symptoms and high rates of recurrence, the treatment and surveillance of $\mathrm{BCa}$ is still costly. ${ }^{23-25}$ Therefore, identifying critical molecular mechanisms and more effective therapeutic targets for $\mathrm{BCa}$ is extremely important.

HDGF is a vital regulator of cancer cell activities, and it plays a broad role in tumorigenesis, such as in cancer cell transformation, apoptosis, angiogenesis and metastasis. ${ }^{26}$ 
A

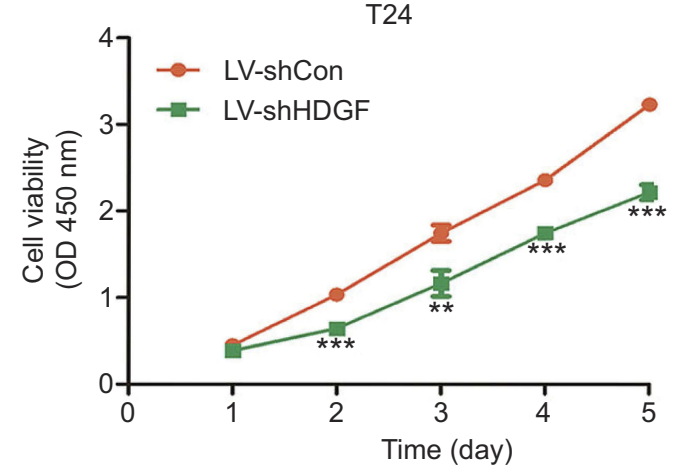

B

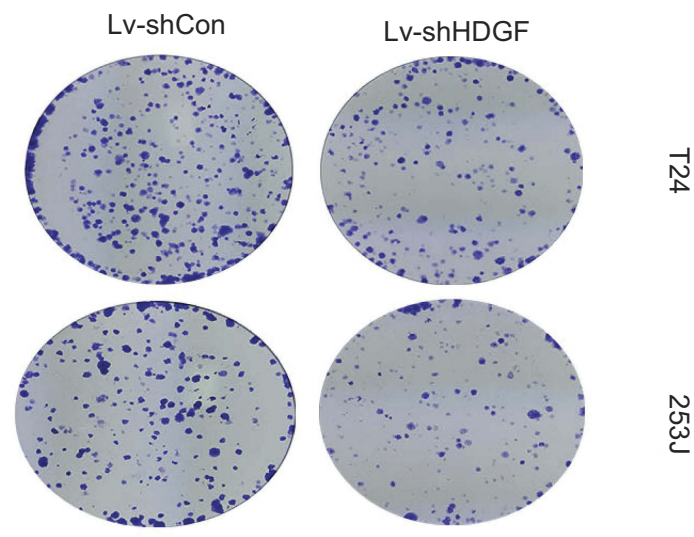

D

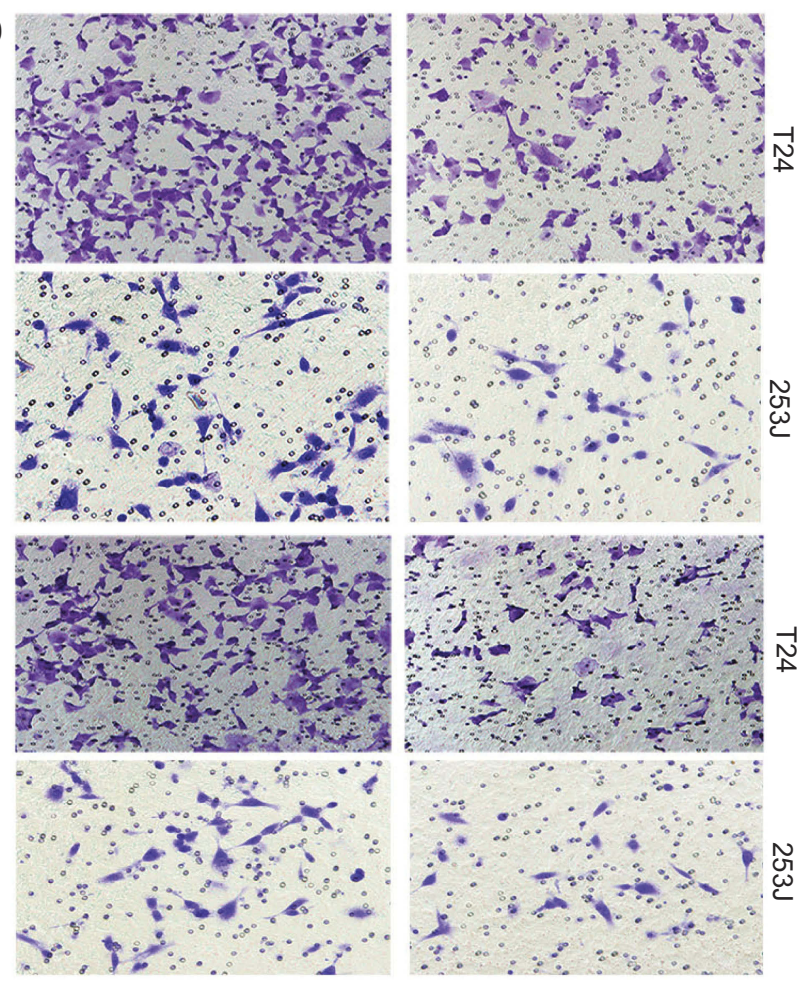

253J

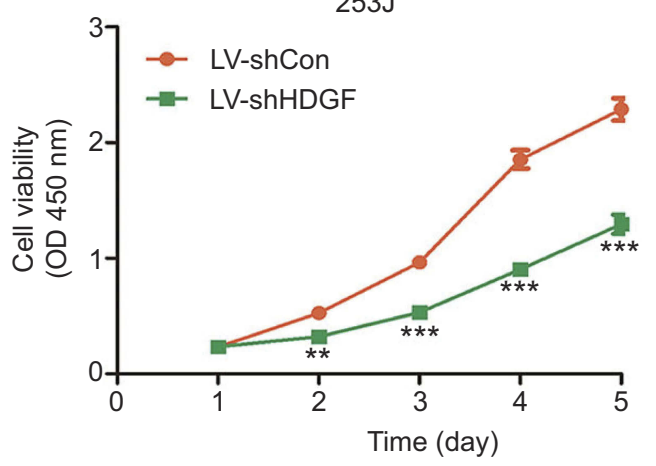

C

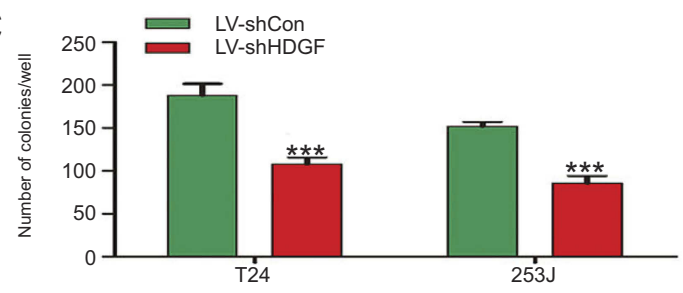

E

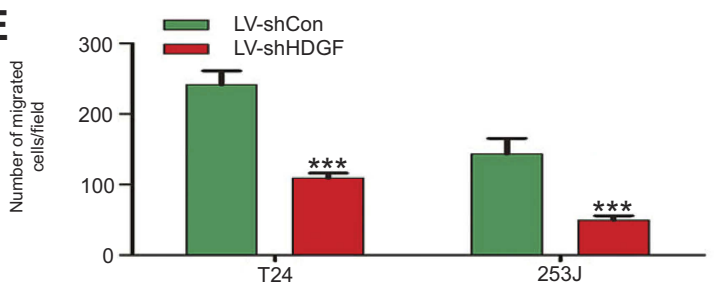

G

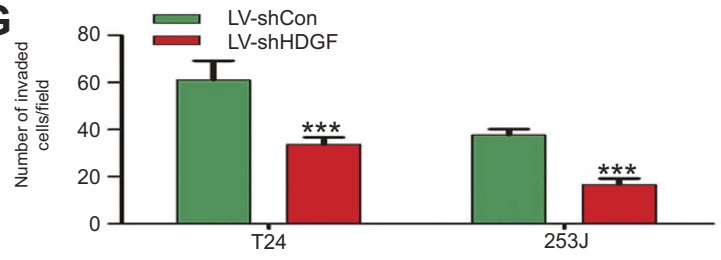

H

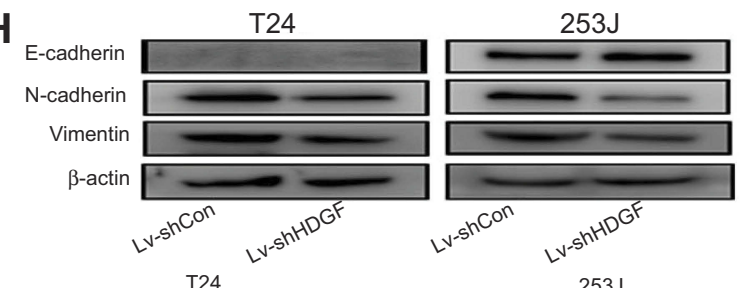

I

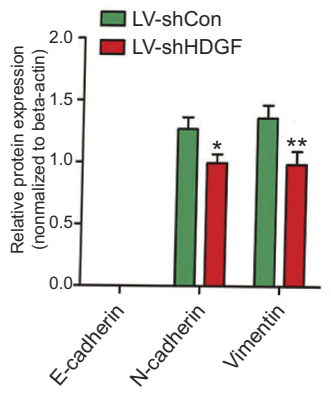

Figure 3 Knockdown of HDGF dramatically inhibits the proliferation, migration and invasion of BCa cells. (A) The growth curves of BCa cells infected with Lv-shCon or Lv-shHDGF were determined by CCK-8 assay. (B-C) Representative images of T24 and 253] cells colony information after infection with Lv-shCon or Lv-shHDGF. (D-E) Transwell migration assay in T24 and 253j cells with stable HDGF knockdown and control plasmid expression; (F-G) Transwell invasion assay in BCa cells with stable HDGF down-regulated and control. (H) Representative Western blot results of proteins related to EMT in T24 and 253J cells with stable HDGF knockdown and control plasmid. (I) The gray intensity quantification of EMT of T24 and 253J cells. $(* p<0.05 ; * *<<0.01 ; * * *<0.001)$.

Abbreviation: EMT, epithelial-mesenchymal transition. 

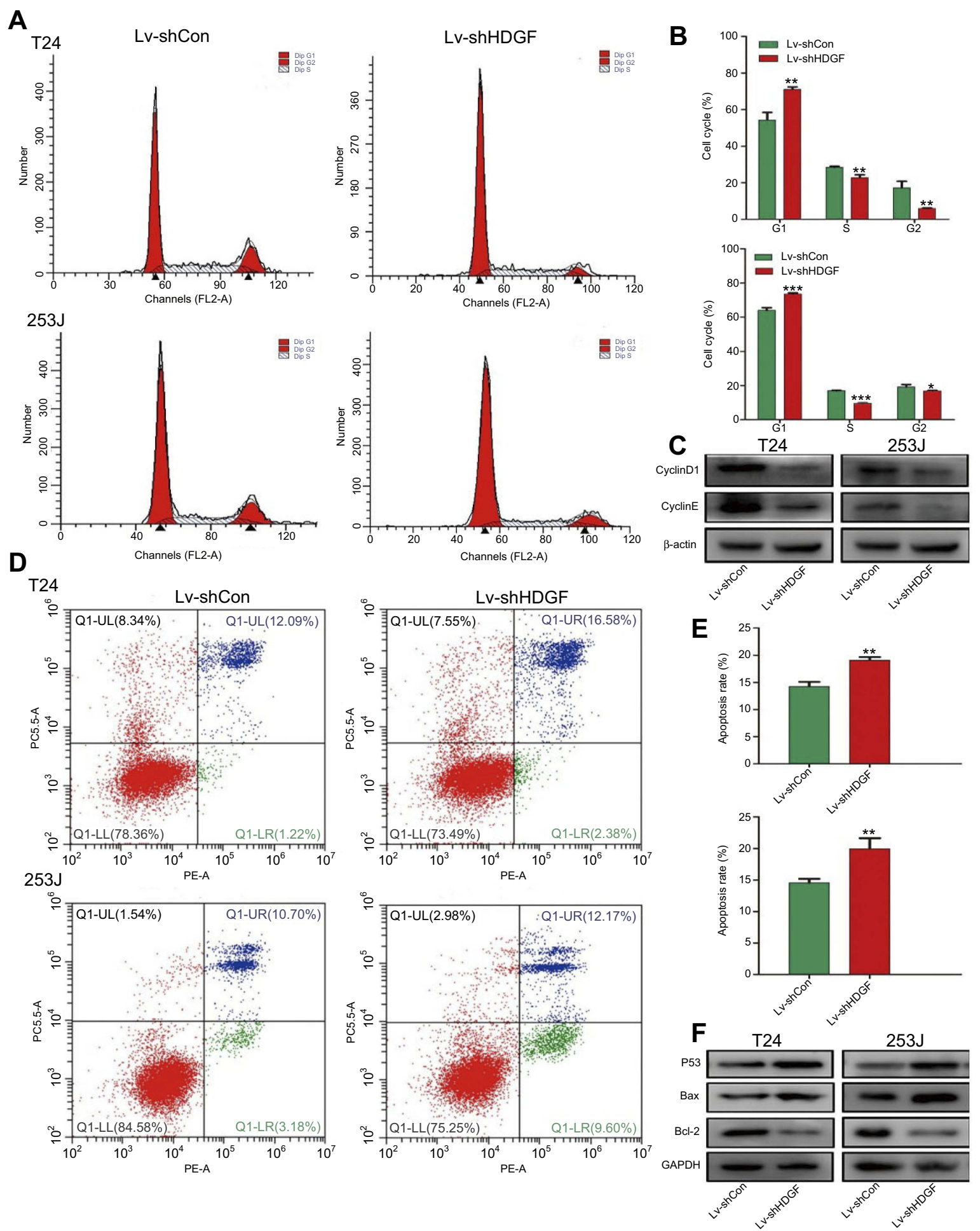

Figure 4 HDGF deletion represses cell cycle and induces apoptosis of BCa cells. (A-B) Representative cell cycle data was measured by flow cytometry in BCa cells infected with Lv-shHDGF or Lv-shCon. (C) Western blot results of proteins related to cell cycle in T24 and 253J cells with stable Hepatoma-derived growth factor (HDGF) knockdown or control expression. (D-E) Apoptosis of BCa cells infected with Lv-shHDGF or Lv-shCon were analyzed by flow cytometry. (F) Proteins involved in apoptosis was analyzed by Western blot. $\left({ }^{*} p<0.05,{ }^{*} p<0.01\right.$; ***p $<0.00$ I).

Although a previous study found that HDGF had the capacity to translocate to the nucleus, where it binds to DNA through its PWWP domain and acts as an oncogene, the concrete mechanism by which HDGF promotes tumor progression remains unclear. ${ }^{27}$ In the present study, by utilizing the ONCOMINE database, we found that the mRNA level 
A

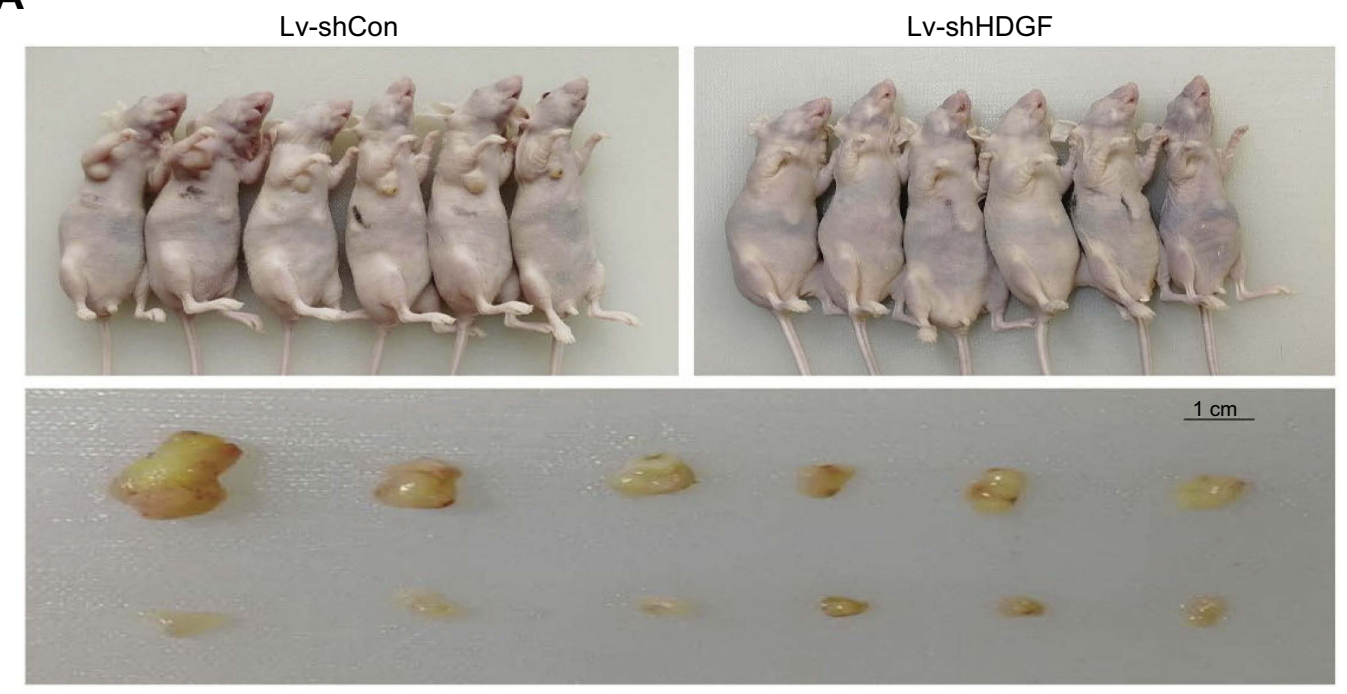

B

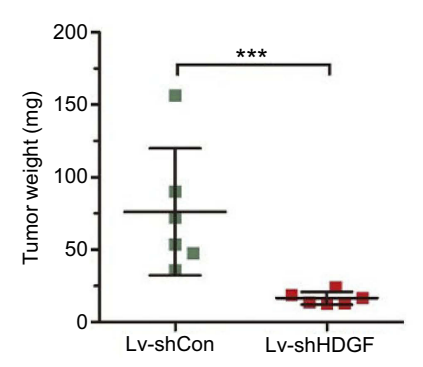

D

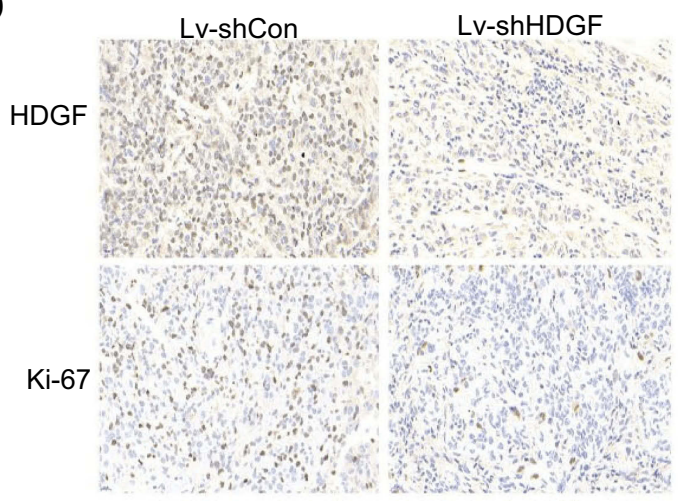

C

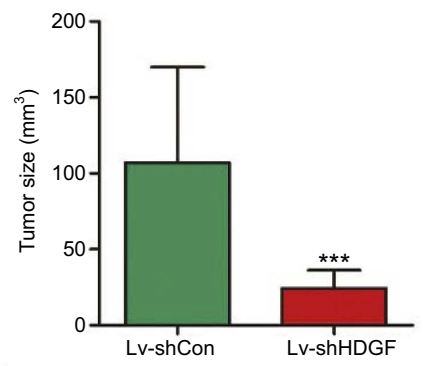

E

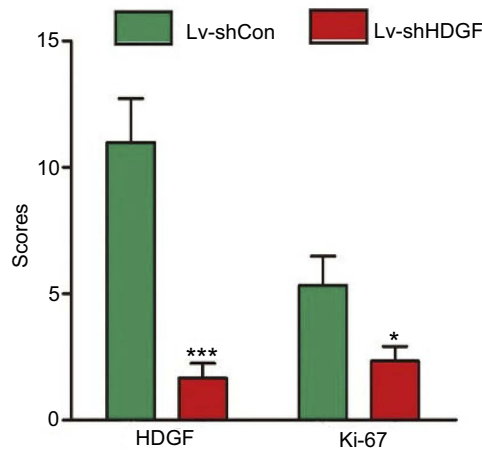

Figure 5 HDGF deletion suppresses T24 cell tumorigenicity in vivo. (A) Representative picture of animals and xenograft tumors. (B) Weights of xenograft tumors derived from T24 cells with HDGF deletion and control. (C) Tumors sizes were measured after tumors were dissected. (D) IHC examination of HDGF and Ki-67 in tumor sections (magnifications $\times 400$ ). (E) Histogram shows IHC scores in control and Hepatoma-derived growth factor (HDGF) deletion group. $\left({ }^{*} p<0.05\right.$; $\left.*^{* *} p<0.00 \mathrm{I}\right)$.

of HDGF was significantly higher in $\mathrm{BCa}$ tissues than in normal tissues and that its level was elevated in MIBC compared to NMIBC tissues. Furthermore, the survival data from the ONCOMINE datasets indicated that HDGF overexpression predicted poor CSS. The above results indicate that elevated levels of HDGF are closely related to the occurrence and progression of $\mathrm{BCa}$. However, until now, no study has focused on the relationship between HDGF and BCa. Therefore, we carried out the present study to verify whether HDGF is a credible candidate biomarker of BCa.
In this study, the mRNA level of HGDF in T24 and $253 \mathrm{~J}$ cells was downregulated by the lentivirus-mediated RNA interference system. As is well known, lentiviruses have the capacity to integrate into the genome of host cells; thus, they are extensively used as vectors for shRNA expression. ${ }^{28}$ Some studies showed that HDGF depletion significantly reduced cancer cell proliferation, migration and invasion, including in gallbladder cancer, gastric cancer, and human glioma cells, ${ }^{29-31}$ but in contrast to the above results, Guo, Z., et al found that 
A

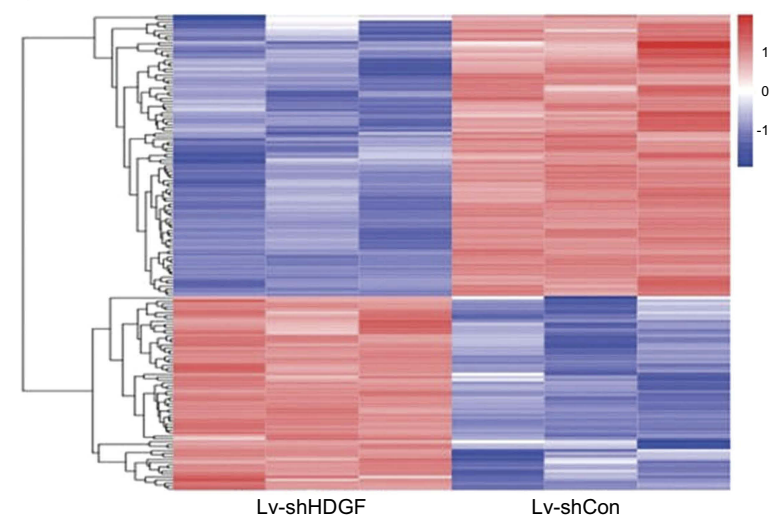

C
B

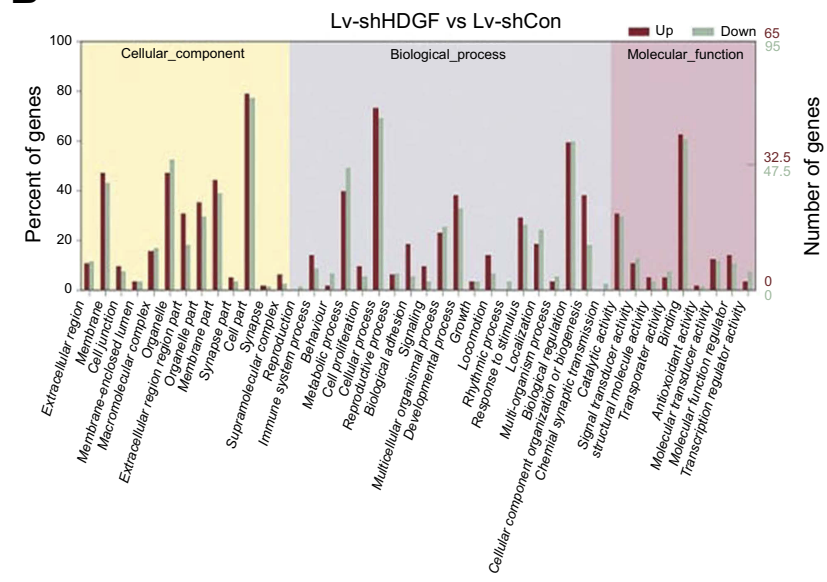

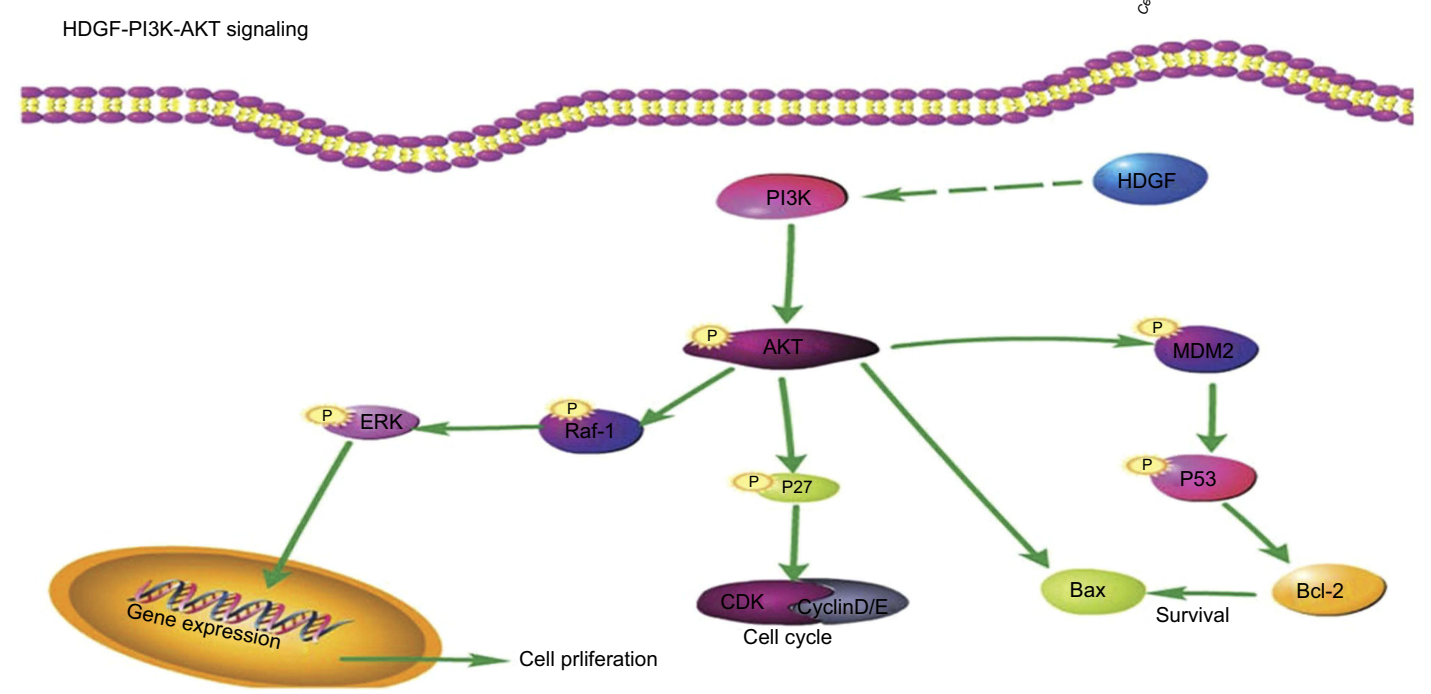

\section{D}

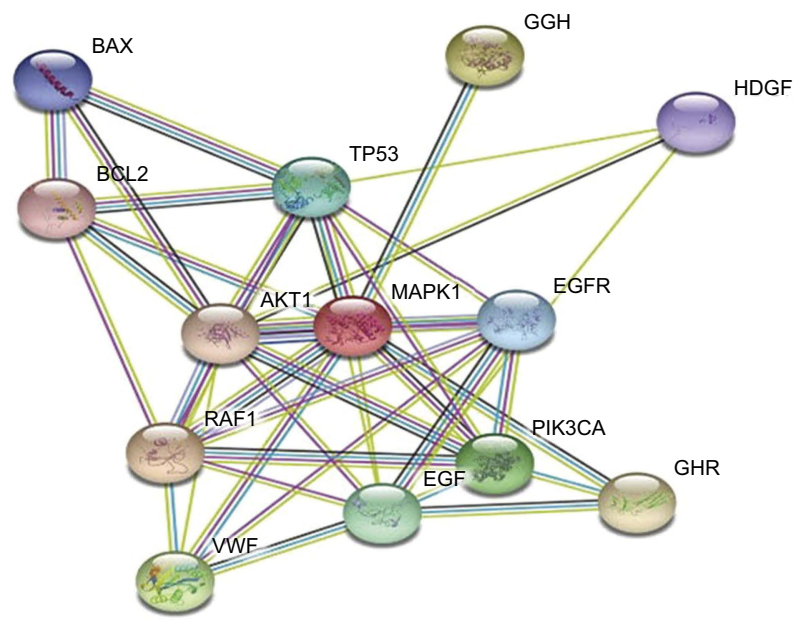

Figure 6 HDGF downregulated affects PI3K-AKT pathway. (A) Heat map representing unsupervised hierarchical clustering of mRNA expression levels in 253J cells infected with Lv-shHDGF or Lv-shCon. Red and Blue indicate high and low expression respectively. (B) Go analysis including the cellular component, biological process and molecular function was performed on DEGs. (C) Hepatoma-derived growth factor (HDGF) positively regulates PI3K-AKT signaling pathway based on KEGG analysis. (D) $\mathrm{PPI}$ analysis of HDGF and the PI3K-AKT pathway related genes.

downregulation of HDGF stimulated cell migration and invasion in breast cancer. ${ }^{32}$ We first investigated the correlations between HDGF expression and $\mathrm{BCa}$, and we found that HDGF deletion significantly inhibited the malignant phenotype of T24 and 253J cells, including proliferation, colony formation, migration and invasion. 


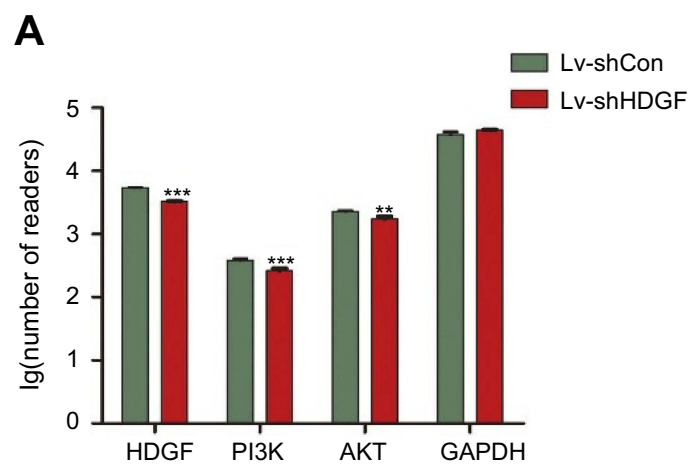

B

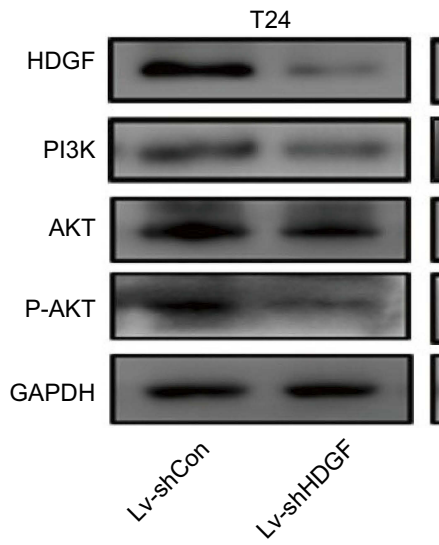

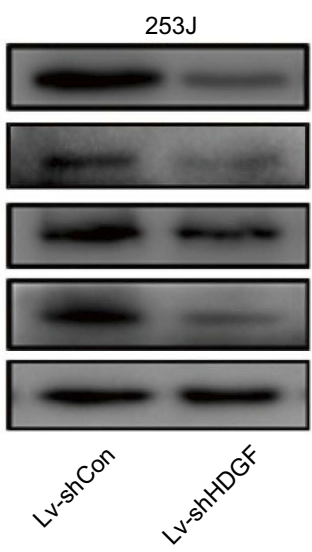

Figure 7 The expression level of key genes related to the PI3K-AKT pathway. (A) RAN-seq analysis indicates mRNA level of HDGF, PI3K and AKT in 253J cells with stable Hepatoma-derived growth factor (HDGF)knockdown and control expression. (B) Representative Western blot results of proteins related to PI3K-AKT pathway in 253J cells infected with Lv-shHDGF or Lv-shCon. $(* p<0.05$, **p<0.0I; ***p<0.00I).

Similar to our findings, the results based on the ONCOMINE database also indicated that HDGF overexpression was closely related to muscular invasion and lymph node metastasis in BCa. It has been well established that EMT is the initiation of tumor invasion and metastasis, ${ }^{33}$ therefore, key protein levels of EMT were analyzed. In accordance with the previous study, E-cadherin was found to be negatively expressed in T24 cells.34,35 Western blot analysis showed that the protein levels of N-cadherin and vimentin were decreased but that Ecadherin was increased in HDGF-downregulated cells. These results provide evidence for a strong relationship between HDGF and cell migration and invasion.

The proliferation and viability of cells were closely related to the cell cycle and apoptosis, ${ }^{36}$ therefore, flow cytometry was performed to assess $\mathrm{BCa}$ cell cycle distribution and apoptosis. It was found that knockdown of HDGF significantly increased the component of G1 phase and promoted apoptosis in T24 and 253J cells. The checkpoint protein expression levels of the cell cycle (cyclin D1 and cyclin E) and apoptosis (P53, Bax and Bcl-2) were also changed with HDGF deletion. Similarly, previous reports demonstrated that downregulated HDGF cells arrested in G1 phase and had increased percentages of apoptotic cells in Ewing's sarcoma and human glioma cells, ${ }^{37,38}$ which is in full support of our results.

In addition, many studies have indicated that HDGF is closely related to tumor growth in xenograft models, ${ }^{39-41}$ therefore, xenograft tumor models were constructed in the present study. Our results indicated that HDGF downregulation effectively inhibited tumor growth. IHC staining showed that Ki-67 was obviously downregulated in xenograft tumors with HDGF deletion. Ki-67 is strongly associated with tumor cell growth and has been embraced as a classic proliferation marker in diagnostic surgical pathology. ${ }^{42}$ We first found that HDGF downregulation could inhibit tumorigenicity of $\mathrm{BCa}$ in vivo.

To explore the molecular mechanism of HDGF regulation in cell fate, RNA sequencing was conducted. The results showed that 162 genes were differentially expressed between HDGF downregulated 253J cells and control cells. Of 162 genes, 66 were overexpressed, and others were downregulated. GO analysis indicated that DEGs were involved in cell proliferation, growth, cellular process, signaling and biological regulation. KEGG analysis demonstrated that HDGF deletion was likely to regulate cell proliferation, survival and cell cycle through the PI3K-AKT axis. Previous studies indicated that PI3 kinase was involved in regulating agonist-stimulated membrane trafficking events and that the PI3K-AKT pathway was involved in many instances of human cancer occurrence and progression, including prostate cancer, colorectal cancer and breast cancer. ${ }^{43-46}$ In the present study, Western blotting showed that the expression levels of PI3K and pAKT were downregulated in HDGF deletion cancer cells, and gene expression levels of their downstream regulators were also changed, including Cyclin D1, Cyclin E, P53, $\mathrm{Bax}$, and Bcl-2. Although our results strongly support the promoting effect of HDGF on BCa formation, the underlying molecular mechanism of the potential interaction between HDGF and PI3K-AKT activation needs to be further explored. 


\section{Conclusion}

In conclusion, our study indicates that HDGF deletion inhibits cell proliferation and viability by arresting cell cycle progression and promoting cell apoptosis. We also verify that HDGF is closely related to the migration and invasion of $\mathrm{BCa}$ cells. The RNA-sequencing analysis shows that HDGF affects BCa cell carcinogenesis associated with the PI3K-AKT pathway. These findings suggest that HDGF may be a promising prognostic indicator and a novel therapeutic candidate in $\mathrm{BCa}$.

\section{Acknowledgment}

This study was supported by financial grants from the National Natural Science Foundation of China(grant Nos: 81502213 and 81372335) (https://isisn.nsfc.gov.cn/egrantweb/), the Natural Science Foundation of Shandong Province (grant Nos: ZR201709230247 and ZR2015HM046), the Science Foundation of Qilu Hospital of Shandong University (grant Nos: 2017-QLHL01) and the Focused Research and Development Program of Shandong Province (grant Nos: 2016GSF201171 and GG201703180001).

\section{Author contributions}

All authors contributed to data analysis, drafting or revising the article, gave final approval of the version to be published, and agree to be accountable for all aspects for the work.

\section{Disclosure}

The authors report no conflicts of interest in this work.

\section{References}

1. Ferlay J, Soerjomataram I, Dikshit R, et al. Cancer incidence and mortality worldwide: sources, methods and major patterns in GLOBOCAN 2012. Int J Cancer. 2015;136(5):E359-E386. doi:10.1002/ijc.29210

2. Bray F, Ferlay J, Soerjomataram I, et al. Global cancer statistics 2018: GLOBOCAN estimates of incidence and mortality worldwide for 36 cancers in 185 countries. CA Cancer J Clin. 2018;68(6):394-424. doi:10.3322/caac. 21492

3. Jiang B, Hailong S, Yuan J, et al. Identification of oncogenic long noncoding RNA SNHG12 and DUXAP8 in human bladder cancer through a comprehensive profiling analysis. Biomed Pharmacother. 2018;108:500-507. doi:10.1016/j.biopha.2018.09.025

4. Karsh L, Shore N, Soloway M, et al. Double-blind, randomized, placebo-controlled studies evaluating apaziquone (E09, Qapzola) intravesical instillation post transurethral resection of bladder tumors for the treatment of low-risk non-muscle invasive bladder cancer. Bladder Cancer. 2018;4(3):293-301. doi:10.3233/BLC-180166

5. Goodspeed A, Jean A, Theodorescu D, et al. A gene expression signature predicts bladder cancer cell line sensitivity to EGFR inhibition. Bladder Cancer. 2018;4(3):269-282. doi:10.3233/BLC-170161
6. Siddiqui MR, Grant C, Sanford T, et al. Current clinical trials in nonmuscle invasive bladder cancer. Urol Oncol. 2017;35(8):516-527. doi:10.1016/j.urolonc.2017.06.043

7. Vashistha V, Quinn DI, Dorff TB, et al. Current and recent clinical trials for perioperative systemic therapy for muscle invasive bladder cancer: a systematic review. BMC Cancer. 2014;14:966. doi:10.1186/ 1471-2407-14-966

8. Chen M, Lv JM, Ye JQ, et al. Disruption of serine/threonine protein phosphatase 5 inhibits tumorigenesis of urinary bladder cancer cells. Int J Oncol. 2017;51(1):39-48. doi:10.3892/ijo.2017.3997

9. Nakamura H, Izumoto $\mathrm{Y}$, Kambe $\mathrm{H}$, et al. Molecular cloning of complementary DNA for a novel human hepatoma-derived growth factor. Its homology with high mobility group-1 protein. J Biol Chem. 1994;269(40):25143-25149.

10. Nakamura H, Kambe H, Egawa T, et al. Partial purification and characterization of human hepatoma-derived growth factor. Clin Chim Acta. 1989;183(3):273-284. doi:10.1016/0009-8981(89)90361-6

11. Gijsbers R, Vets S, de Rijck J, et al. Role of the PWWP domain of lens epithelium-derived growth factor (LEDGF)/p75 cofactor in lentiviral integration targeting. J Biol Chem. 2011;286(48):4181241825. doi:10.1074/jbc.M111.255711

12. Kishima Y, Yamamoto H, Izumoto Y, et al. Hepatoma-derived growth factor stimulates cell growth after translocation to the nucleus by nuclear localization signals. J Biol Chem. 2002;277(12):1031510322. doi:10.1074/jbc.M111122200

13. Chen Z, Qiu S, Lu X. The expression and clinical significance of HDGF in osteosarcoma. Onco Targets Ther. 2015;8:2509-2517. doi:10.2147/OTT.S91708

14. Zhang J, Ren H, Yuan P, et al. Down-regulation of hepatoma-derived growth factor inhibits anchorage-independent growth and invasion of non-small cell lung cancer cells. Cancer Res. 2006;66(1):18-23. doi:10.1158/0008-5472.CAN-04-3905

15. Chang KC, Tai MH, Lin JW, et al. Hepatoma-derived growth factor is a novel prognostic factor for gastrointestinal stromal tumors. Int $J$ Cancer. 2007;121(5):1059-1065. doi:10.1002/ijc.22803

16. Uyama H, Tomita Y, Nakamura H, et al. Hepatoma-derived growth factor is a novel prognostic factor for patients with pancreatic cancer. Clin Cancer Res. 2006;12(20 Pt 1):6043-6048. doi:10.1158/10780432.CCR-06-1064

17. Yamamoto S, Tomita Y, Hoshida Y, et al. Expression of hepatomaderived growth factor is correlated with lymph node metastasis and prognosis of gastric carcinoma. Clin Cancer Res. 2006;12(1):117122. doi:10.1158/1078-0432.CCR-05-1347

18. Uhlen M, Oksvold P, Fagerberg L, et al. Towards a knowledge-based human protein atlas. Nat Biotechnol. 2010;28(12):1248-1250. doi:10.1038/nbt1210-1248

19. Hu R, Wang MQ, Niu WB, et al. SKA3 promotes cell proliferation and migration in cervical cancer by activating the PI3K/Akt signaling pathway. Cancer Cell Int. 2018;18:183. doi:10.1186/s12935-018-0670-4

20. Liu C, Wang L, Jiang Q, et al. Hepatoma-derived growth factor and DDX5 promote carcinogenesis and progression of endometrial cancer by activating beta-catenin. Front Oncol. 2019;9:211. doi:10.3389/ fonc.2019.00211

21. Wang MJ, Zhang H, Li J, et al. microRNA-98 inhibits the proliferation, invasion, migration and promotes apoptosis of breast cancer cells by binding to HMGA2. Biosci Rep. 2018;38(5). doi: 10.1042/ BSR20180571.

22. Martinez Rodriguez RH, Buisan Rueda O, Ibarz L. Bladder cancer: present and future. Med Clin (Barc). 2017;149(10):449-455. doi:10.1016/j.medcli.2017.06.009

23. van Lingen AV, Witjes JA. Current intravesical therapy for nonmuscle invasive bladder cancer. Expert Opin Biol Ther. 2013;13 (10):1371-1385. doi:10.1517/14712598.2013.824421

24. Tian DW, Liu SL, Jiang LM, et al. RAB38 promotes bladder cancer growth by promoting cell proliferation and motility. World $J$ Urol. 2018. doi:10.1007/s00345-018-2596-9 
25. la Rosa H-D, Acker A,M, Kumar RA, et al. Epigenetics application in the diagnosis and treatment of bladder cancer. Can J Urol. 2015;22 (5):7947-7951.

26. Bao C, Wang J, Ma W, et al. HDGF: a novel jack-of-all-trades in cancer. Future Oncol. 2014;10(16):2675-2685. doi:10.2217/ fon. 14.194

27. Min X, Wen J, Zhao L, et al. Role of hepatoma-derived growth factor in promoting de novo lipogenesis and tumorigenesis in hepatocellular carcinoma. Mol Oncol. 2018;12(9):1480-1497. doi:10.1002/1878-0261.12357

28. Manilla P, Rebello T, Afable C, et al. Regulatory considerations for novel gene therapy products: a review of the process leading to the first clinical lentiviral vector. Hum Gene Ther. 2005;16(1):17-25. doi:10.1089/hum.2005.16.17

29. Li M, Shen J, Wu X, et al. Downregulated expression of hepatomaderived growth factor (HDGF) reduces gallbladder cancer cell proliferation and invasion. Med Oncol. 2013;30(2):587. doi:10.1007/ s12032-013-0587-7

30. Mao J, Xu Z, Fang Y, et al. Hepatoma-derived growth factor involved in the carcinogenesis of gastric epithelial cells through promotion of cell proliferation by Erk1/2 activation. Cancer Sci. 2008;99 (11):2120-2127. doi:10.1111/j.1349-7006.2008.00928.x

31. Zhang A, Long W, Guo Z, et al. Downregulation of hepatomaderived growth factor suppresses the malignant phenotype of U87 human glioma cells. Oncol Rep. 2012;28(1):62-68. doi:10.3892/ or.2012.1768

32. Guo Z, He Y, Wang S, et al. Various effects of hepatoma-derived growth factor on cell growth, migration and invasion of breast cancer and prostate cancer cells. Oncol Rep. 2011;26(2):511-517. doi:10.3892/or.2011.1295

33. Jayachandran A, Dhungel B, Steel JC. Epithelial-to-mesenchymal plasticity of cancer stem cells: therapeutic targets in hepatocellular carcinoma. J Hematol Oncol. 2016;9(1):74. doi:10.1186/s13045-016-0307-9

34. Bindels EM, Vermey M, de Both NJ, et al. Influence of the microenvironment on invasiveness of human bladder carcinoma cell lines. Virchows Arch. 2001;439(4):552-559.

35. Sun Y, Cheng MK, Griffiths TR, et al. Inhibition of STAT signalling in bladder cancer by diindolylmethane: relevance to cell adhesion, migration and proliferation. Curr Cancer Drug Targets. 2013;13 (1):57-68.
36. Evan GI, Vousden KH. Proliferation, cell cycle and apoptosis in cancer. Nature. 2001;411(6835):342-348. doi:10.1038/35077213

37. Yang Y, Li H, Zhang F, et al. Clinical and biological significance of hepatoma-derived growth factor in Ewing's sarcoma. J Pathol. 2013;231(3):323-334. doi:10.1002/path.4241

38. Hsu SS, Chen CH, Liu GS, et al. Tumorigenesis and prognostic role of hepatoma-derived growth factor in human gliomas. $J$ Neurooncol. 2012;107(1):101-109. doi:10.1007/s11060-011-0733-z

39. Enomoto H, Nakamura H, Liu W, et al. Down-regulation of HDGF inhibits the growth of hepatocellular carcinoma cells in vitro and in vivo. Anticancer Res. 2015;35(12):6475-6479.

40. Zhou Y, Zhou N, Fang W, et al. Overexpressed HDGF as an independent prognostic factor is involved in poor prognosis in Chinese patients with liver cancer. Diagn Pathol. 2010;5:58. doi:10.1186/ 1746-1596-5-58

41. Ren H, Chu Z, Mao L. Antibodies targeting hepatoma-derived growth factor as a novel strategy in treating lung cancer. Mol Cancer Ther. 2009;8(5):1106-1112. doi:10.1158/1535-7163.MCT-08-0779

42. Brown DC, Gatter KC. Ki67 protein: the immaculate deception? Histopathology. 2002;40(1):2-11.

43. Kumar A, Priyamvada S, Soni V. et al. Angiotensin II inhibits Pglycoprotein in intestinal epithelial cells. Acta Physiol (Oxf). 2019; e13332. doi:10.1111/apha.13332

44. Wu XL, Wang LK, Yang DD, et al. Effects of Glut1 gene silencing on proliferation, differentiation, and apoptosis of colorectal cancer cells by targeting the TGF-beta/PI3K-AKT-mTOR signaling pathway. $J$ Cell Biochem. 2018;119(2):2356-2367. doi:10.1002/ jcb.26399

45. Ciruelos Gil EM. Targeting the PI3K/AKT/mTOR pathway in estrogen receptor-positive breast cancer. Cancer Treat Rev. 2014;40 (7):862-871. doi:10.1016/j.ctrv.2014.03.004

46. Yan $\mathrm{G}, \mathrm{Ru} \mathrm{Y}, \mathrm{Wu} \mathrm{K}$, et al. GOLM1 promotes prostate cancer progression through activating PI3K-AKT-mTOR signaling. Prostate. 2018;78(3):166-177. doi:10.1002/pros.23461 


\section{Supplementary material}
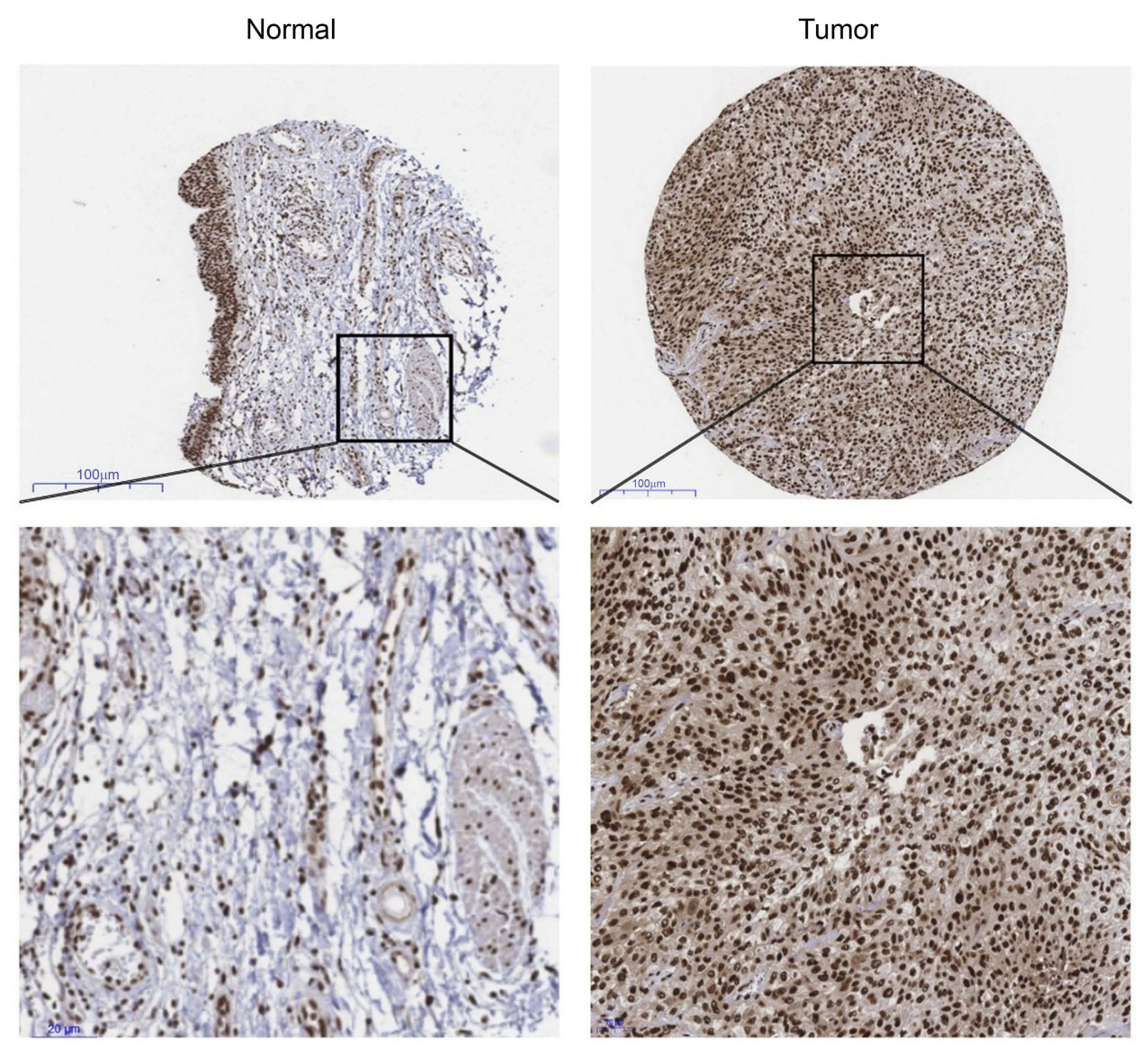

Figure SI Representative image of IHC staining of HDGF in normal bladder tissues and BCa tissues (upper: $\times 40$; lower: $\times 400)($ Date comes from public database-The Human Protein Atlas portal (www.proteinatlas.org)).

\section{Publish your work in this journal}

Cancer Management and Research is an international, peer-reviewed open access journal focusing on cancer research and the optimal use of preventative and integrated treatment interventions to achieve improved outcomes, enhanced survival and quality of life for the cancer patient.
The manuscript management system is completely online and includes a very quick and fair peer-review system, which is all easy to use. Visit http://www.dovepress.com/testimonials.php to read real quotes from published authors. 